\title{
Períodos e ambientes de secagem na qualidade de sementes de Genipa americana L.
}

\section{Periods and dry environments in the seeds quality of Genipa americana $\mathrm{L}$.}

\author{
Lucicléia Mendes de Oliveira $^{1 *}$; Edna de Oliveira Silva ${ }^{2}$; Riselane de Lucena \\ Alcântara Bruno ${ }^{3}$; Edna Ursulino Alves ${ }^{3}$
}

\section{Resumo}

Genipa americana L. é uma árvore tropical, pertencente à família Rubiaceae, fornece frutos que são consumidos in natura e vem sendo explorados cada vez mais como matéria-prima de licor, vinho, refresco e também o uso da madeira branca para confecção de vários produtos. A secagem de sementes dessa espécie pode ser feita pelo método natural e/ou artificial. Dessa forma, este trabalho teve por objetivo avaliar o efeito da secagem natural, em diferentes ambientes e períodos, na qualidade fisiológica das sementes de Genipa americana. As sementes foram submetidas à determinação do teor de água após o beneficiamento em cada período de secagem (0, 24, 48, 72, 96, 120, 144 e 168 horas). Para a avaliação do efeito dos ambientes (laboratório e ambiente telado) e períodos de secagem foram realizados os seguintes testes: emergência em ambiente telado, índice de velocidade de emergência, comprimento de plântulas e massa da matéria seca. A secagem de sementes de jenipapeiro pode ser feita em ambiente telado (valores médios de temperatura de $33^{\circ} \mathrm{C}$ e umidade relativa do ar de $70 \%$ ) durante 24 horas ou em laboratório (valores médios de $28^{\circ} \mathrm{C}$ e umidade relativa do ar de $75 \%$ ) por até 48 horas sem comprometer a qualidade fisiológica.

Palavras-chave: Dessecação. Jenipapo. Teor de água.

\begin{abstract}
Genipa americana $\mathrm{L}$. is a tropical tree belonging to Rubiaceae family, providing fruit that are consumed in natura and is being increasingly explored as raw material to liquor, wine, soft drink and also the use of white wood for making various products. The seeds drying this species can be made using natural and or artificial methods. Thus, this study aimed to evaluate the effects of natural drying, in different periods and ambient, in the physiological quality of Genipa americana seeds. Seeds were submitted to the determination of moisture content after processing and drying of each period $(0,24,48,72,96,120$, 144 and 168 hours). To evaluate the effects of ambient (laboratory and greenhouse) and drying periods were performed the following tests: emergence in greenhouse, emergence speed index, seedling length and dry weight. Drying seed genipa can be done in a greenhouse (temperature of $33^{\circ} \mathrm{C}$ with relative humidity of $70 \%$ ) for 24 hours or laboratory environment (temperature of $28^{\circ} \mathrm{C}$ with relative humidity of $75 \%$ ) for 48 hours without compromising the physiological quality.
\end{abstract}

Key words: Desiccation. Jenipapo. Humitidy degree.

\footnotetext{
1 Bióloga, M.Sc., Doutoranda do Programa de Pós Graduação em Ciências e Tecnologia de Sementes, UFPel, FAEM, Rua Quinze de novembro, n.409, Ap. 406, Pelotas, RS,CEP. 96015-000. E-mail: lucicleiabiologa@hotmail.com

2 Eng. Agr., M.Sc., Doutoranda do Programa de Pós Graduação em Agronomia, Departamento de Fitotecnia e Ciências Ambientais, CCA, UFPB, Areia,PB. E-mail: ed.os@hotmail.com

3 Eng. Agr., Prof ${ }^{a}$. Dr ${ }^{\mathrm{a}}$, Universidade Federal da Paraíba, CCA/Campus II, Cidade Universitária, s/n, Areia, PB, CEP. $58397-000$. Bolsista do CNPq.E-mail: riselane@pq.cnpq.br, ednaursulino@cca.ufpb.br

* Autor para correspondência
} 


\section{Introdução}

O jenipapeiro é uma árvore tropical, pertencente à família Rubiaceae, possui caule reto e alto, fornece frutos que são consumidos in natura e vem sendo explorados cada vez mais como matéria-prima de licor, vinho e refresco. Além disso, esta árvore frutífera fornece madeira branca para confecção de vários produtos. $\mathrm{O}$ fruto é uma baga, contendo numerosas sementes no núcleo, de cor parda e achatada (GOMES, 1989). A espécie suporta longos períodos sob condições de alagamento, sendo promissora para recuperação de áreas degradadas em ambientes de mata ciliar no Estado de São Paulo (BARBOSA et al., 1989). Para a obtenção de sementes, recomenda-se colher os frutos diretamente da árvore quando estes iniciarem a queda espontânea ou recolhê-los no chão, e amontoá-los em sacos plásticos até a decomposição da polpa (LORENZI, 1998).

Quanto ao potencial de armazenamento, as sementes em geral são classificadas em dois grupos distintos: ortodoxas e recalcitrantes. As ortodoxas mantêm-se viáveis após a secagem até o teor de água de até $5 \%$ e permanecem viáveis por longos períodos sob baixas temperaturas, enquanto as recalcitrantes perdem rapidamente a viabilidade se forem secadas a teores de água muito baixos (ROBERTS, 1973). E ainda há as sementes que apresentam comportamento intermediário entre os citados, tolerando a dessecação entre 7 e 10\% de teor de água e não toleram baixas temperaturas durante períodos de tempo prolongado, conforme verificado por Carvalho, Silva e Davide (2006) em várias espécies florestais.

A viabilidade das sementes é reduzida quando o teor de água atinge valores inferiores àqueles considerados críticos, e quando se apresenta igual ou inferior àqueles considerados letais, ocorre à perda total da viabilidade (HONG; ELLIS, 1992), pois a sensibilidade das sementes recalcitrantes à dessecação depende da espécie, sendo os teores, crítico e letal, de água relativamente altos, respectivamente, de 27 a 38\% (CHIN, 1988; ANDRADE; PEREIRA, 1997) e de 12 a $22 \%$ (FERREIRA; SANTOS, 1992; ANDRADE; PEREIRA, 1997). Além disso, a perda de água estrutural durante o processo de secagem pode causar alteração dos sistemas metabólicos e das membranas resultando no início do processo de deterioração (FARRANT; PAMMENTER; BERJAK, 1988).

O jenipapeiro é uma espécie de fácil propagação por sementes, apresentando entre 83 e $92 \%$ de emergência. No entanto, o processo é lento, assíncrono e com baixa uniformidade. Essas características são fontes de grande heterogeneidade no desenvolvimento das plantas, o que pode dificultar a condução dos tratos culturais em viveiros de produção de mudas. Suas sementes não apresentam dormência fisiológica e são classificadas como intermediárias, suportando armazenamento por até 60 dias (FERREIRA et al., 2007).

O processo de secagem ocorre mediante duas fases, sendo a primeira, a transferência de água da superfície da semente para o ar que a circunda e, a segunda o movimento da água do interior da semente para a superfície (CARVALHO; NAKAGAWA, 2000). A secagem das sementes, além de contribuir para a preservação da qualidade fisiológica durante o armazenamento, possibilita a antecipação da colheita (GARCIA et al., 2004). Em sementes ortodoxas, a redução do teor de água retarda os processos fisiológicos como a respiração e o consumo das reservas nutritivas armazenadas em seus tecidos de reserva, prevenindo a proliferação de fungos e bactérias, enquanto para as sementes recalcitrantes ou intermediárias, a secagem pode levar a morte do embrião. Nas sementes florestais, a secagem é feita por método natural e artificial, o primeiro refere-se à exposição dos frutos e/ou sementes a ação dos ventos e energia solar, enquanto o outro ocorre pela movimentação da massa de ar de secagem por meio de equipamentos especiais (MEDEIROS; EIRA, 2006). 
Desta forma, este trabalho teve por objetivo avaliar o efeito da secagem natural, em diferentes ambientes e períodos, na qualidade fisiológica das sementes de jenipapeiro.

\section{Material e Métodos}

A presente pesquisa foi desenvolvida no Laboratório de Análise de Sementes (LAS) do Centro de Ciências Agrárias da Universidade Federal da Paraíba (UFPB), campus II, em AreiaPB.

Os frutos de jenipapeiro foram coletados quando estavam no estágio de maturação próprio para o consumo humano. Foram colhidos de árvores matrizes no município de Areia-PB, sendo o clima da região, segundo classificação de Köppen, do tipo As', caracterizado por quente $\left(25^{\circ} \mathrm{C}\right)$ e úmido $(85 \%)$, com chuvas de outono-inverno (1.200 $\mathrm{mm}$ anuais) e período de estiagem de 5 a 6 meses, com solos moderadamente ácidos (GONDIM; FERNANDEZ, 1980). Em seguida, as sementes foram extraídas de forma manual com peneira em água corrente e areia para auxiliar na remoção da mucilagem. Após esta operação, as sementes foram colocadas para secar sobre papel toalha em bandejas, sendo a secagem avaliada em dois ambientes: laboratório (valores médios de temperatura de $28^{\circ} \mathrm{C}$ e umidade relativa do ar de $75 \%$ ) e em ambiente telado (valores médios de temperatura de $33^{\circ} \mathrm{C}$ e umidade relativa do ar de $70 \%)$.

Os períodos de secagem foram: 0, 24, 48, 72, 96, 120, 144 e 168 horas. Em cada período determinouse: o teor de água das sementes, a emergência de plântulas, o índice de velocidade de emergência, o comprimento e a massa seca de plântulas.

$\mathrm{O}$ teor de água foi obtido pelo método da estufa a $105 \pm 3^{\circ} \mathrm{C}$, por 24 horas (BRASIL, 2009) utilizandose quatro subamostras, nas quais as sementes cobriam o fundo do recipiente de $4 \mathrm{~cm}$ de diâmetro.

O teste de emergência de plântulas foi realizado em substrato areia, em bandejas plásticas com quatro subamostras de 25 sementes, totalizando 100 sementes em cada combinação de período e ambiente de secagem. O encerramento do teste ocorreu aos 20 dias, quando houve a estabilização da emergência das plântulas. A contagem das plântulas foi realizada quando os cotilédones estavam acima do substrato, com os resultados expressos em porcentagem.

O Índice de Velocidade de Emergência (IVE) foi determinado mediante contagem diária das plântulas emersas até o final do teste, sendo o cálculo realizado por meio da fórmula proposta por Maguire (1962).

Para a avaliação do comprimento de plântulas, ao final do teste de emergência, as plântulas normais foram retiradas com o auxílio de uma mangueira com jato de água, e em seguida levadas ao laboratório para aferir as medições desde a raiz até o meristema apical, com os resultados expressos em centímetros por plântula.

Para a determinação da massa da matéria seca das plântulas, as mesmas foram submetidas à secagem em estufa regulada a $65^{\circ} \mathrm{C}$, até atingirem massa constante, com os resultados expressos em gramas.

O delineamento utilizado foi inteiramente casualizado, com os tratamentos distribuídos em esquema fatorial $2 \times 8$, representados por dois ambientes (laboratório e ambiente telado) e oito tempos de secagem $(0,24,48,72,96,120,144$ e 168 horas), com quatro repetições. Os dados foram submetidos à análise de variância, sendo as médias (períodos) submetidas à análise de regressão polinomial e as médias (ambientes) comparadas pelo teste de Tukey $(\mathrm{p}<0,01)$.

\section{Resultados e Discussão}

O teor de água das sementes de jenipapeiro (Figura 1) diminui progressivamente ao longo dos períodos de secagem nos dois ambientes, registrando-se às 36 horas valores semelhantes, 
em torno de $30 \%$ de água, para as sementes dos dois ambientes. A partir das 48 horas se observa diferenciação entre os ambientes de secagem, culminando com os menores valores às 120 horas.
Neste momento a secagem provocou uma redução média de aproximadamente $49 \%$ do teor de água, passando de 54 para 10\% (laboratório) e 58 para 5\% (ambiente telado).

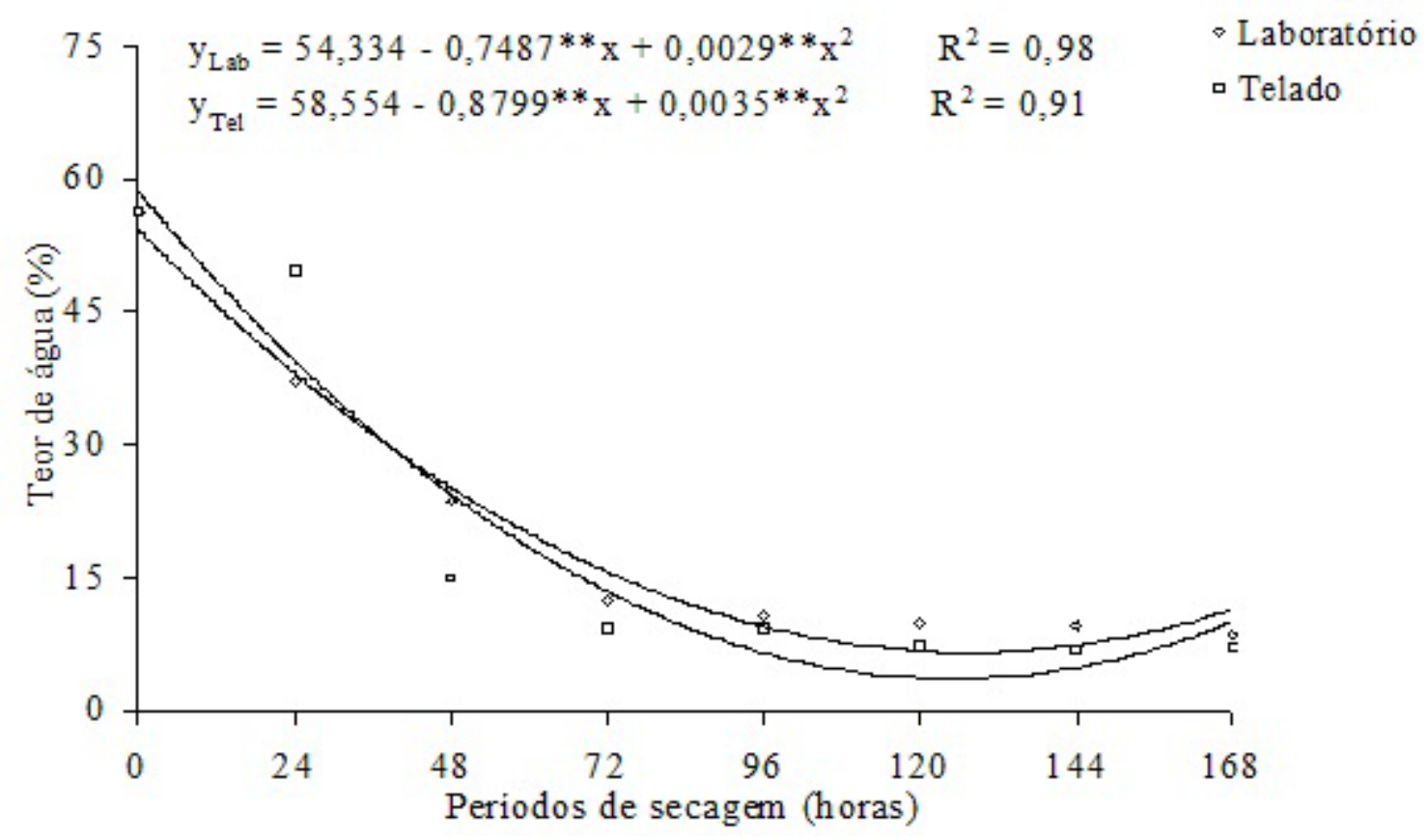

Figura 1. Teor de água de sementes de jenipapeiro (G. americana L.) em função da secagem em laboratório e ambiente telado por diferentes períodos.

De acordo com a (Figura 1), fica evidente que a secagem em ambiente telado proporcionou maior redução na umidade das sementes do que em ambiente de laboratório, levando-se em consideração a diferença de temperatura nos dois ambientes, sendo a temperatura média do ambiente telado de $33^{\circ} \mathrm{C}$ e umidade relativa do ar de $70 \%$; enquanto o ambiente de laboratório com temperatura média de $28^{\circ} \mathrm{C}$ e umidade relativa do ar de $75 \%$. Provavelmente a temperatura do ambiente telado por ser mais alta acelerou a velocidade de secagem e pode ter provocado algum dano físico e fisiológico na semente, partindo do princípio de que sementes de comportamento intermediário não toleram dessecação inferior a faixa do teor de água entre 7 e 10\%, conforme descrito por Carvalho, Silva e Davide (2006).

A porcentagem de emergência das plântulas de jenipapeiro em ambiente de laboratório foi máxima (92\%) no período de 24 horas de secagem, momento em que o teor de água se encontrava acima de $40 \%$, porém abaixo de $5 \%$ não ocorreu germinação. A secagem em laboratório à $28^{\circ} \mathrm{C}$, cuja temperatura foi inferior ao ambiente telado $33^{\circ} \mathrm{C}$, ainda favoreceu a emergência das plântulas até as 168 horas, destacandose o ambiente de laboratório como aquele que proporcionou uma maior emergência.

A ausência da germinação das sementes de jenipapeiro está relacionada à diminuição do teor de água, fato também observado por Vieira e Gusmão (2006) durante o armazenamento das sementes aos 60 dias com teor de água de 3,34\%, verificando-se que as mesmas possuem longevidade relativamente curta. O comportamento das mesmas durante o armazenamento é intermediário, razão pela qual não toleram a dessecação a níveis extremamente reduzidos (CARVALHO; NASCIMENTO, 2000).

Em ambiente telado constatou-se redução linear na 
porcentagem de emergência de plântulas a partir das primeiras horas de secagem até alcançar valor zero antes de 144 horas. Desta forma, acredita-se que o teor de água da semente de jenipapeiro inferior a $10 \%$ (Figura 1) pode ter comprometido a emergência(Figura 2), provocando algum tipo de dano por secagem, uma vez que as sementes com teor de água muito elevado foram expostas ao ambiente telado e fechado em que a temperatura se elevava durante o dia. Segundo Guimarães (1999) durante o processo de formação da semente, a mesma passa por diferentes níveis de secagem naturalmente. Esse autor comenta ainda que as sementes podem ser armazenadas com teores de água entre 10 e $13 \%$, fase em que o metabolismo e a taxa de respiração são baixos, porém teores de água inferiores a $4 \%$ provocam danos irreversíveis.

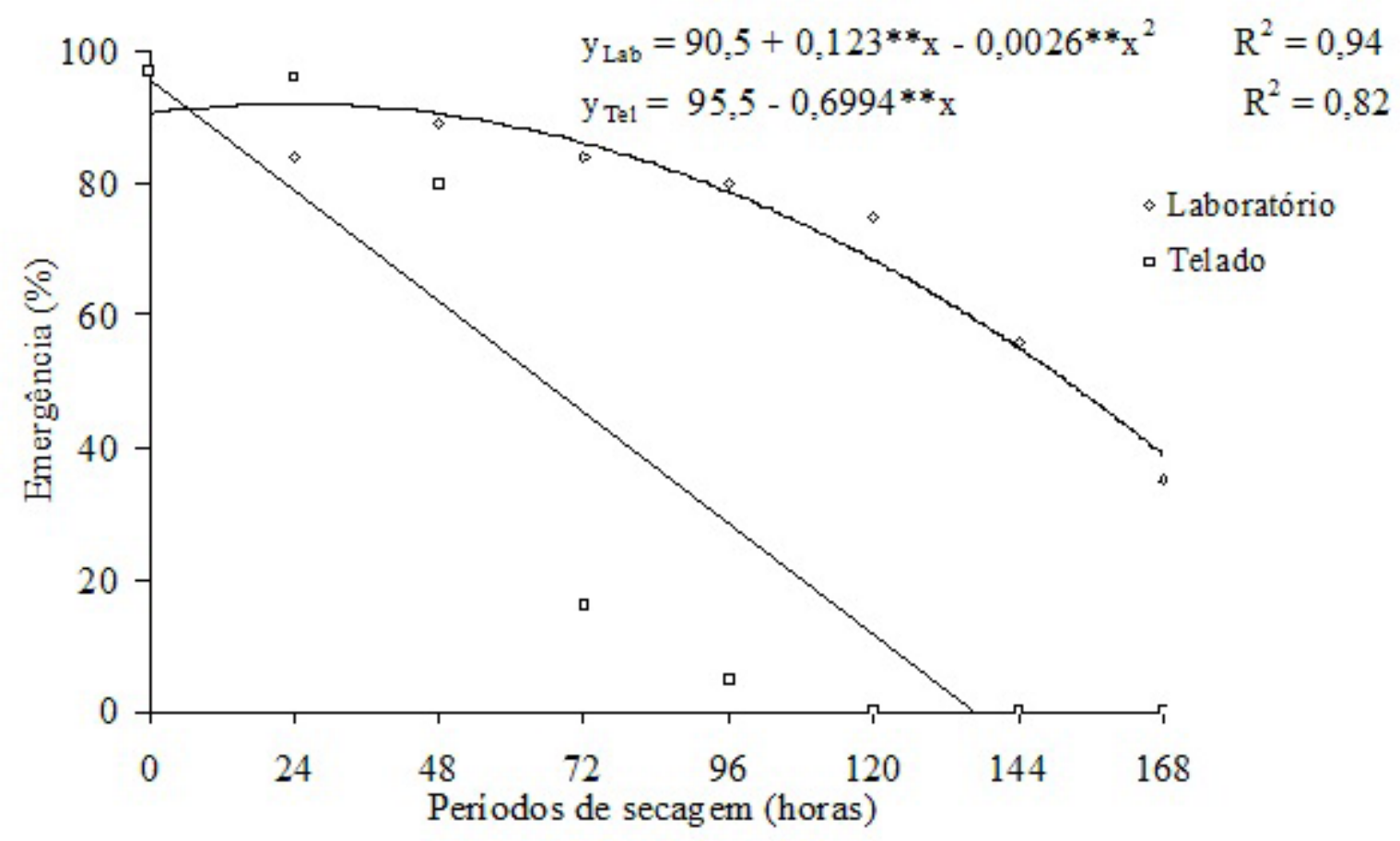

Figura 2. Emergência de plântulas de jenipapeiro (G. americana L.) oriundas de sementes submetidas à secagem em laboratório e ambiente telado por diferentes períodos.

Quando as sementes recalcitrantes são desidratadas após a coleta, ocorre a perda gradual da viabilidade com o dessecamento, passando por um ponto crítico até atingir o teor de água chamado letal. Comportamento semelhante foi observado por Andrade, Schorn e Nogueira (2005) em sementes de Archantophoenix alexandrae Wendl and Drude, onde observaram que a partir das 78 horas de secagem as sementes estavam com $24,84 \%$ de umidade considerando-se como teor de água letal. Da mesma forma, Nazário, Ferreira e Rebouças (2008) em sementes de Cynometra bauhiniifolia Benthan verificaram que o teor de água crítico situou-se entre 46,6 e $41,4 \%$, enquanto o teor de umidade letal ficou entre 28,2 e $23,9 \%$, o que são características típicas de sementes recalcitrantes.

Para o índice de velocidade de emergência o comportamento foi semelhante ao observado na emergência de plântulas (Figura 3). A partir de 24 horas foi observada uma redução na velocidade de emergência em função do período de secagem, sendo mais pronunciada no ambiente telado, enquanto no laboratório o máximo vigor foi alcançado às 17 horas de secagem, reduzindo a partir daí de forma lenta, devido à diferença de temperatura e umidade relativa do ar nos dois locais como já mencionado. 


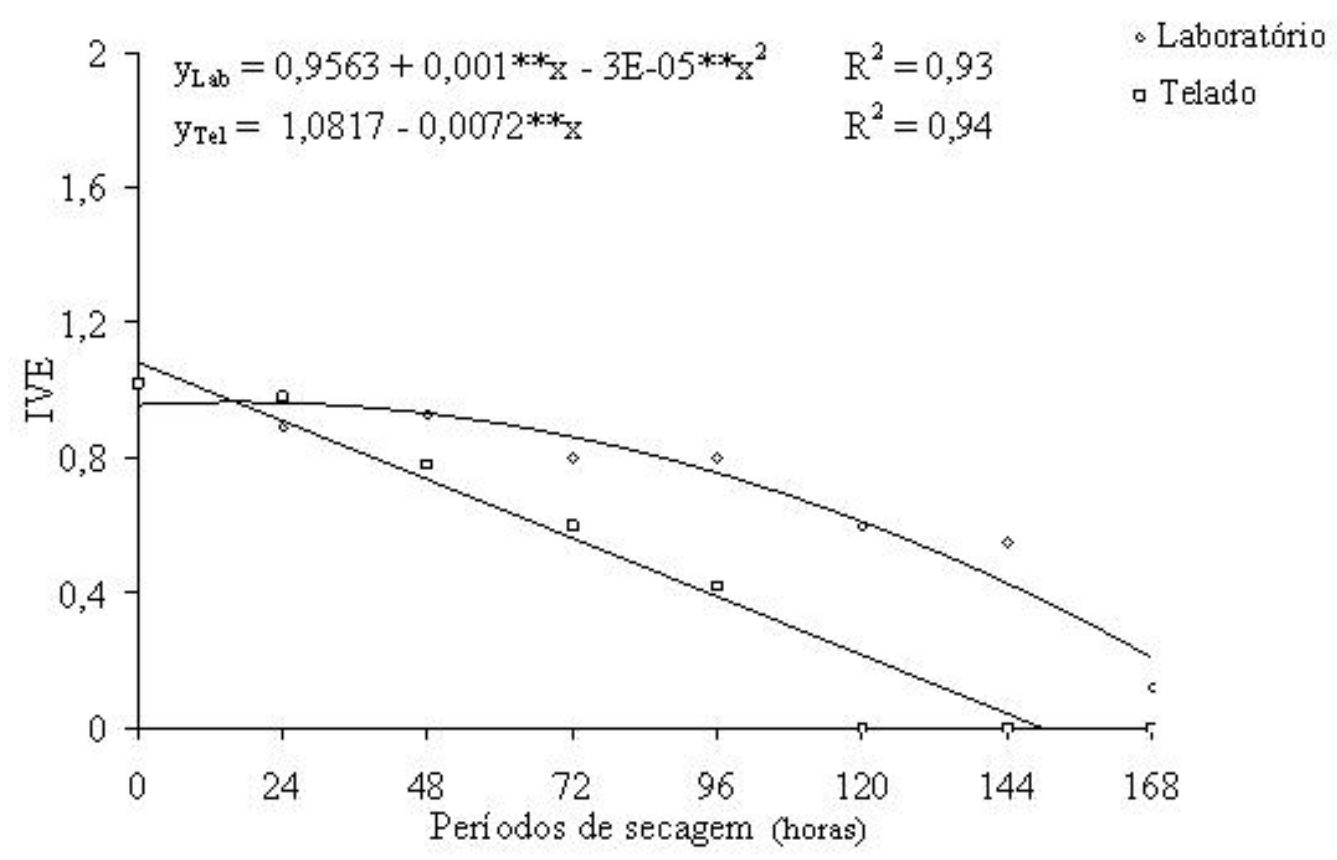

Figura 3. Índice de velocidade de emergência de plântulas de jenipapeiro (G. americana L.) oriundas de sementes submetidas à secagem em laboratório e ambiente telado por diferentes períodos.

O crescimento das plântulas (Figura 4) também foi afetado pela secagem, de forma equivalente ao evidenciado na porcentagem e no índice de velocidade de emergência de plântulas. Dessa forma, as sementes podem ser submetidas à secagem em ambiente de laboratório por até 31 horas, enquanto no ambiente telado até 24 horas. Provavelmente a temperatura de secagem pode ter provocado alterações fisiológicas, e com isso, comprometeu a disponibilidade das reservas energéticas para o suprimento das plântulas.

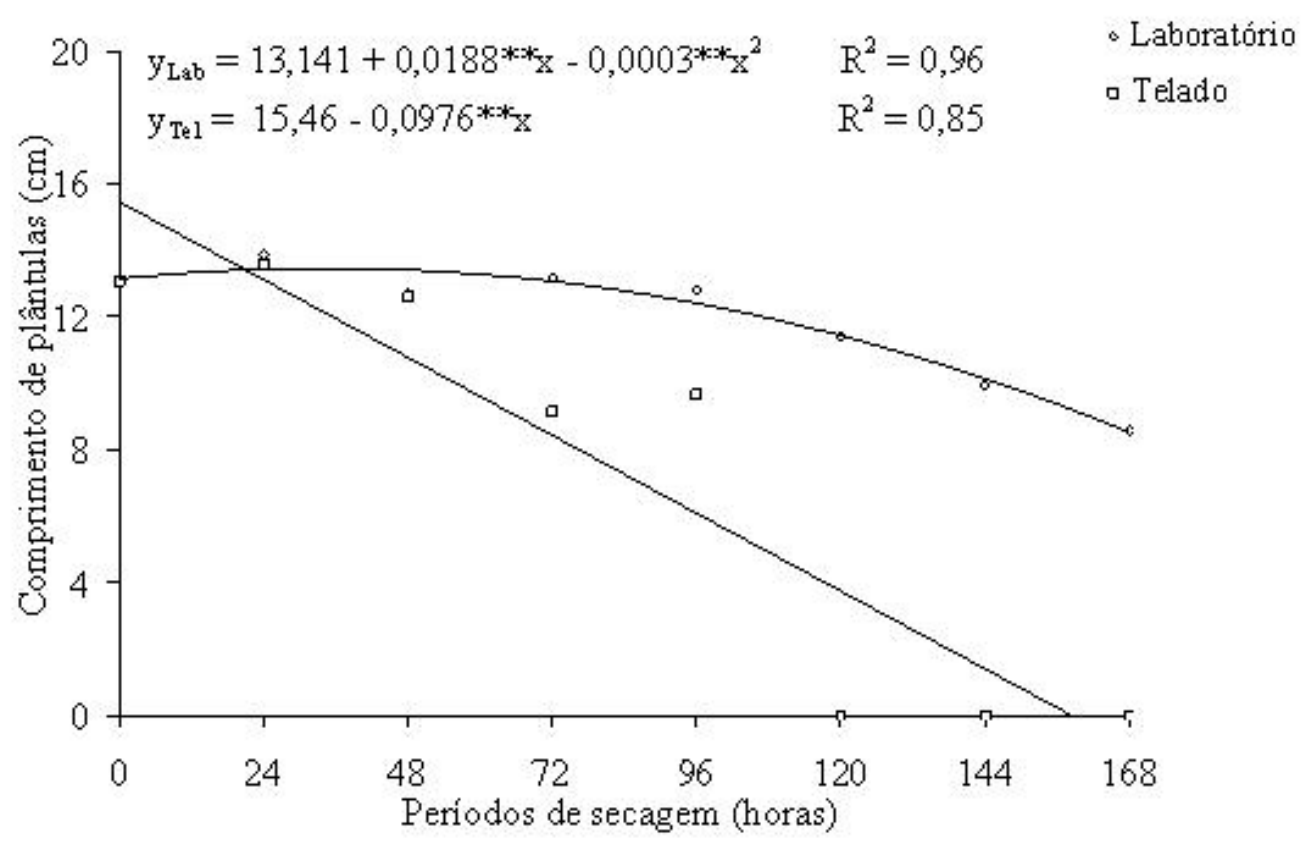

Figura 4. Comprimento de plântulas de jenipapeiro (G. americana L.) oriundas de sementes submetidas à secagem em laboratório e ambiente telado por diferentes períodos. 
Como observado anteriormente nos testes de emergência, índice de velocidade de emergência e comprimento de plântulas, os resultados de massa da matéria seca das plântulas (Figura 5) também foram semelhantes. Desta forma, constatou-se que as sementes de jenipapeiro podem ser expostas a secagem, em laboratório durante 43 horas, enquanto àquelas submetidas a secagem em telado reduziram drasticamente o vigor a partir das 24 horas. Cabe ressaltar que a redução do teor de água a valores inferiores a $9 \%$ provocou a perda de viabilidade dessas sementes, conforme pode ser constatado no período de 120 horas de secagem no ambiente telado.

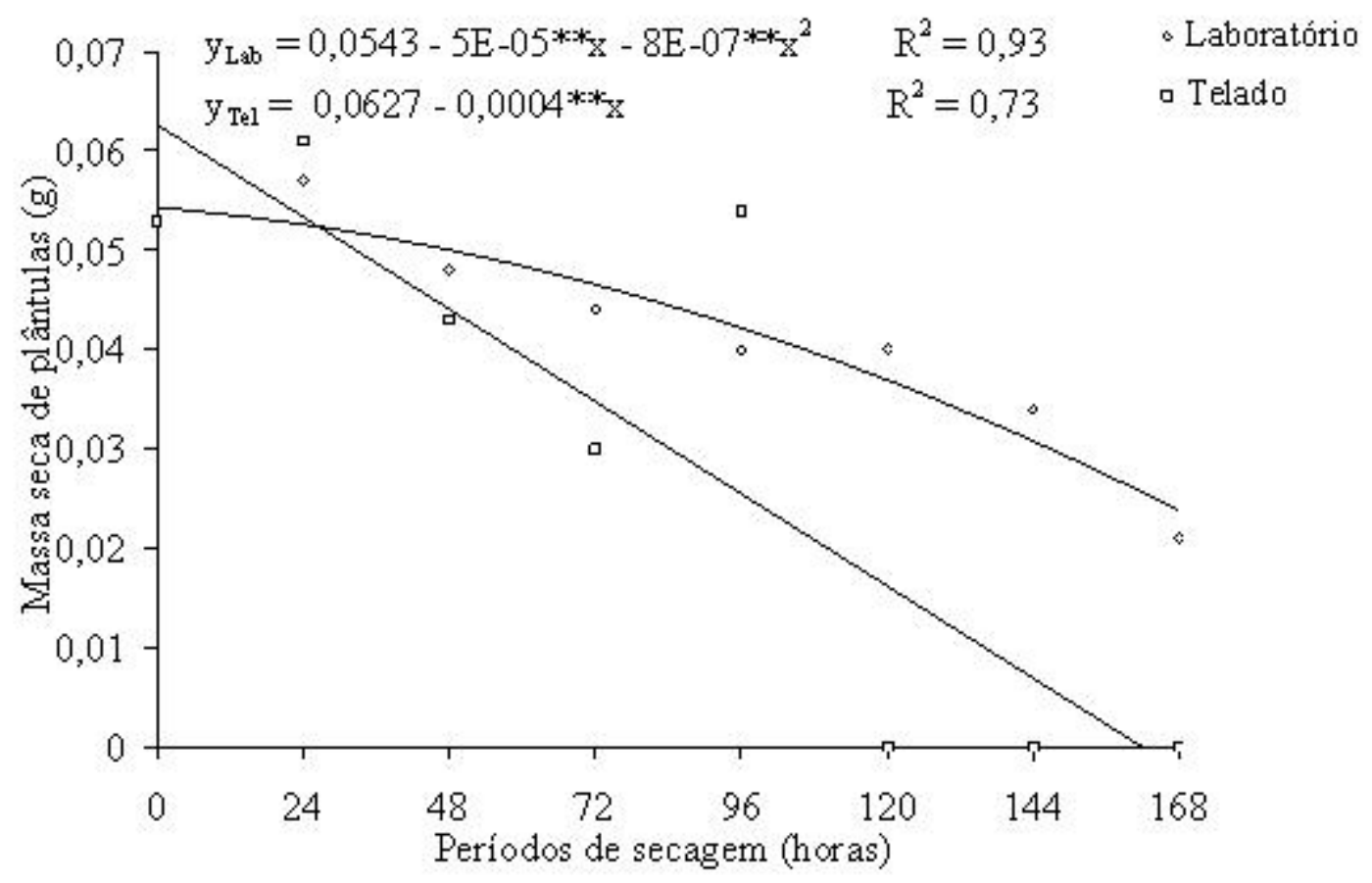

Figura 5. Massa da matéria seca de plântulas de jenipapeiro (G. americana L.) oriundas de sementes submetidas à secagem em laboratório e ambiente telado por diferentes períodos.

\section{Conclusão}

A secagem de sementes de jenipapeiro pode ser feita em ambiente telado (valores médios de temperatura de $33^{\circ} \mathrm{C}$ e umidade relativa do ar de $70 \%$ ) durante 24 horas ou em laboratório (valores médios de $28^{\circ} \mathrm{C}$ e umidade relativa do ar de $75 \%$ ) por até 48 horas sem comprometer a qualidade fisiológica.

\section{Referências}

ANDRADE, A. C. S.; PEREIRA, T. S. Comportamento de armazenamento de sementes de palmiteiro (Euterpe edulis Mart.). Pesquisa Agropecuária Brasileira, Brasília, v. 32, n. 10, p. 987-991, 1997.
ANDRADE, R. R.; SCHORN, L. A.; NOGUEIRA, A. A. Tolerância à dessecação em sementes de Archantophoenix alexandrae Wendl. and Drude (palmeira real australiana). Ambiência, Guarapuava, v. 1, n. 2, p. 279-288, 2005.

BARBOSA, L. M.; BARBOSA, J. M.; BATISTA, E. A.; MANTOVANI, W.; VERONESE, S. A.; ANDREANI, R. Ensaios para estabelecimento de modelos para recuperação de áreas degradadas de matas ciliares, Mogi-Guaçú (SP). Nota Prévia. In: SIMPÓSIO SOBRE MATA CILIAR, 1., 1989, Campinas. Anais... Campinas: Fundação CARGILL, 1989. p. 268-283.

BRASIL, Ministério da Agricultura, Pecuária e Abastecimento. Regras para análise de sementes. Brasília: MAPA/ACS, 2009. 399 p.

CARVALHO, J. E. U.; NASCIMENTO, W. M. O. Sensibilidade de sementes de jenipapo (Genipa americana L.) ao dessecamento e ao congelamento. 
Revista Brasileira de Fruticultura, Jaboticabal, v. 22, n. 1, p. 53-56, 2000.

CARVALHO, L. R.; SILVA, E. A. A.; DAVIDE, A. C. Classificação de sementes florestais quanto ao comportamento no armazenamento. Revista Brasileira de Sementes, Pelotas, v. 28, n. 2, p. 15-25, 2006.

CARVALHO, N. M.; NAKAGAWA, J. Sementes: ciência, tecnologia e produção. 4. ed. Jaboticabal: FUNEP, 2000. 588 p.

CHIN, H. F. Recalcitrant seeds: a status report. Rome: International Board for Plant Genetic Resources, 1988. $28 \mathrm{p}$.

FARRANT, J. M.; PAMMENTER, N. W.; BERJAK, P. Recalcitrance - a current assessment. Seed Science and Technology, Zurich, v. 16, n. 1, p. 1555-1566, 1988.

FERREIRA, S. A. N.; SANTOS, L. A. Viabilidade de sementes de pupunha (Bactris gasipaes Kunth.). Acta Amazonica, Manaus, v. 22, n. 3, p. 303-307, 1992.

FERREIRA, W. R.; RANAL, M.; DORNELES, M. C.; SANTANA. Crescimento de mudas de Genipa americana $\mathrm{L}$. submetidas a condições de pré-semeadura. Revista Brasileira de Biociências, Porto Alegre, v. 5, p. 1026-1028, 2007. Suplemento 2.

GARCIA, D. C.; BARROS, A. C. S. A.; PESKE, S. T.; MENEZES, N. L. A secagem de sementes. Ciência Rural, Santa Maria, v. 34, n. 2, p. 603-608, 2004.

GOMES, R. P. Fruticultura brasileira. 11. ed. São Paulo: Nobel, 1989. 446 p.

GONDIM, A. W. A.; FERNADEZ, B. Probabilidade de chuvas para o município de Areia- PB. Agropecuária Técnica, Areia, v. 1, n. 1, p. 55-63, 1980.

GUIMARÃES, R. M. Fisiologia de sementes. 1999. Apostila (Curso de Especialização Pós-Graduação "Lato Senso" por Tutoria à Distância: Produção e Tecnologia de Sementes) - Universidade Federal de Lavras/UFLA, Lavras.

HONG, T. D.; ELLIS, R. H. Opttimum air-dry seed storage enviroments for Arabica coffee. Seed Science and Technology, Zurich, v. 20, n. 3, p. 547-560, 1992.

LORENZI, H. Árvores brasileiras: manual de identificação e cultivo de plantas arbóreas nativas do Brasil. 2. ed. Nova Odessa: Plantarum, 1998. 352 p.

MAGUIRE, L. D. Speed of germination - aid in selection and evolution for seedling emergence and vigor. Crop Science, Madison, v. 2, n. 2, p. 176-177, 1962.

MEDEIROS, A. C. S.; EIRA, M. T. S. Comportamento fisiológico, secagem e armazenamento de sementes florestais nativas. Colombo: EMBRAPA, 2006. 13 p.
(Circular técnica, 127).

NAZÁRIO, P.; FERREIRA, S. A. N.; REBOUÇAS, E.

R. Germinação de sementes de Cynometra bauhiniifolia Benthan (jutairana) em função do dessecamento e da manutenção sob condição úmida. Acta Amazonica, Manaus, v. 38, n. 3, p. 439-444, 2008.

ROBERTS, E. H. Predicting the storage life of seeds. Seed Science and Technology, Zürich, v. 1, n. 4, p. 499514, 1973.

VIEIRA, F. A.; GUSMÃO, E. Efeitos de giberelinas, fungicidas e do armazenamento na germinação de sementes de Genipa americana L. (Rubiaceae). Cerne, Lavras, v. 12, n. 2, p. 137-144, 2006. 